\title{
Study of Insulin Resistance in Women with Preeclampsia
}

\author{
${ }^{1}$ Amit D Sonagra, ${ }^{2}$ Zahoorunissa Deba, ${ }^{3}$ Asmabi Makandar, ${ }^{4}$ Shivaleela M Biradar
}

\section{ABSTRACT}

Introduction: The root cause of preeclampsia is placental ischemia due to impaired trophoblastic invasion in the uterine spiral arterioles. Ischemic placenta liberates various inflammatory mediators that cause widespread endothelial dysfunction leading to insulin resistance (IR). Increased IR in pregnant females can further lead to high occurrence of maternal and fetal complications.

Objectives: To compare and evaluate the role of measuring IR among women with preeclampsia and normal pregnancy.

Materials and methods: A total of 35 women with preeclampsia and 35 women with normal pregnancy were included in the study as cases and controls, respectively. Fasting plasma glucose (FPG) and fasting plasma insulin (FI) were measured and IR indices, such as FPG to $\mathrm{FI}$ ratio (FGIR), quantitative insulin sensitivity check index (QUICKI), and log FI were calculated. Unpaired Student's t-test was used for comparison. Statistical analysis was done using Statistical Package for the Social Sciences (SPSS) version 17.0.

Results: The mean FI and log FI were significantly higher while QUICKI and FGIR were significantly lower in cases when compared with controls $(p<0.001)$.

Conclusion: As disease advances, IR increases. There is increased risk of maternal and fetal complications in presence of increased IR. Screening of all hypertensive pregnancies for IR and timely intervention may help to improve outcome.

Keywords: Fasting plasma glucose to fasting plasma insulin ratio, Insulin resistance, Preeclampsia, Quantitative insulin sensitivity check index.

How to cite this article: Sonagra AD, Deba Z, Makandar A, Biradar SM. Study of Insulin Resistance in Women with Preeclampsia. Indian J Med Biochem 2017;21(2):127-130.

\footnotetext{
${ }^{1-4}$ Assistant Professor

${ }^{1}$ Department of Biochemistry, Gujarat Medical Education and Research Society Medical College \& Hospital, Ahmedabad Gujarat, India

${ }^{2}$ Department of Biochemistry, Khaja Bandanawaz Institute of Medical Sciences, Gulbarga, Karnataka, India

${ }^{3}$ Department of Biochemistry, East Point College of Medical Sciences \& Research Centre, Bengaluru, Karnataka, India

${ }^{4}$ Department of Biochemistry, BLDE Association's Shri B. M. Patil Medical College, Vijayapur, Karnataka, India

Corresponding Author: Zahoorunissa Deba, Assistant Professor, Department of Biochemistry, Khaja Bandanawaz Institute of Medical Sciences, Gulbarga, Karnataka, India e-mail:
}

\section{Source of support: Nil}

\section{Conflict of interest: None}

\section{INTRODUCTION}

Evidence of knowledge of hypertensive disorders of pregnancy is found in Hippocratic writings (430-330 BC). As stated in Coan prognosis, headache accompanied by heaviness and convulsion during pregnancy should be considered as alarming symptoms. ${ }^{1}$

Overall incidence of preeclampsia is 6 to $8 \%$ of all pregnancies and $10 \%$ of first pregnancies. Approximately 50,000 women die annually from preeclampsia worldwide. It contributes to the death of a woman every 3 minutes worldwide. ${ }^{2}$ It is associated with many maternal complications, such as preterm labor; antepartum hemorrhage; postpartum hemorrhage; hemolysis, elevated liver enzyme levels, and low platelet levels syndrome; and fetal complications, such as intrauterine growth retardation (IUGR). ${ }^{3}$

The working group of the National High Blood Pressure Education Programme (NHBPEP 2000) has defined hypertensive disorders of pregnancy. Any mother who was previously normotensive and nonproteinuric and who develops elevation of blood pressure (BP) $\geq 140 / 90$ $\mathrm{mm} \mathrm{Hg}$ after 20 weeks of gestation (2 reading, at least 6 hours apart) and proteinuria of $\geq 300 \mathrm{mg}$ in 24-hour urine sample or $\geq 1+$ by dipstick method in a random urine sample is defined as preeclampsia. ${ }^{4}$

Adequate invasion of trophoblasts into uterine spiral arterioles is necessary for proper functioning of placenta. Impaired invasion leads to narrowing of uterine arterioles and placental ischemia. ${ }^{5}$ Placental ischemia becomes a causative factor for reduced expression of placental growth factor, vascular endothelial growth factor, nitric oxide, and prostacyclin from vascular endothelium. Expression of antiangiogenic factors, such as soluble Fmslike tyrosine kinase 1 , interleukins (ILs), tumor necrosis factor- $\alpha$ (TNF- $\alpha)$, etc., is increased on the other side. This angiogenic imbalance causes widespread endothelial dysfunction all over the body. ${ }^{6,7}$ Increased levels of TNF- $\alpha$ and ILs cause alterations in the insulin signaling pathway leading to IR. ${ }^{8}$ Increased mortality and morbidity, both in mother and fetus, are associated with increased IR. ${ }^{9}$

This study was done to evaluate status of IR in preeclamptic women and compare with that of normal pregnancy. 


\section{MATERIALS AND METHODS}

Totally, 35 women with preeclampsia and 35 healthy pregnant women were included in a cross-sectional study. Preeclamptic mothers were taken as cases and healthy pregnant mothers were taken as controls after taking informed consent. The Institutional Ethical Committee approved this study.

\section{Inclusion Criteria for Selection of Study Subjects}

- Cases: About 35 diagnosed cases of preeclampsia ${ }^{4}$ in the age group of 20 to 45 years.

- Controls: About 35 healthy pregnant women of $\geq 20$ weeks of gestation after matching for age and gestational period.

\section{Exclusion Criteria}

Women with history of multiple gestation, molar pregnancy, systemic illness, or addiction or medication affecting blood glucose and insulin level were excluded.

\section{Sample Collection}

Women were instructed for 12 hours overnight fasting. About $2 \mathrm{~mL}$ of venous blood was collected in a fluoride ethylenediaminetetraacetic acid vial using proper aseptic precautions. Plasma was separated by centrifugation and used for the estimation of plasma glucose and plasma insulin concentration.

\section{Sample Analysis}

Concentration of FPG was determined by using analytical kit from ERBA Diagnostics Mannheim $\mathrm{GmbH}$ in semi-autoanaylzer (CHEM-5 plus $\mathrm{V}_{2}$, Erba Mannheim) according to glucose oxidase and peroxidase method. ${ }^{10}$ The FI concentration was estimated in Lumax chemiluminescence immunoassay ${ }^{11}$ (CLIA) microplate reader using CLIA kit from Acculite-Monobind.
The IR indices that include FGIR, QUICKI, and log FI were calculated from the values of FPG and FI concentration based on the methods ${ }^{12}$ using the formulas:

$$
\text { QUICKI }=1 /(\log F P G \text { in } \mathrm{mg} / \mathrm{dL}+\log \mathrm{FI} \text { in } \mu \mathrm{IU} / \mathrm{mL})
$$

\section{Statistical Analysis}

Values are presented as mean \pm standard deviation (SD) and the statistical analysis was done using SPSS 17.0 software. Student's unpaired t-test was used for comparison of parameters between two groups. The p-value of less than 0.05 was considered as statistically significant.

\section{RESULTS}

Table 1 shows that the mean levels of systolic and diastolic BP $(p<0.001)$, FPG $(p<0.05), F I$, and log FI $(p<0.001)$ were significantly higher in cases when compared with controls. The mean values of FGIR and QUICKI were significantly lower in cases when compared with controls $(\mathrm{p}<0.001)$. No significant difference was found in period of gestation and age of mother in both the study groups.

Table 2, Graphs 1 and 2 show correlation between study parameters and BP among study subjects. It shows that FI and log FI are positively correlated with systolic and diastolic BPs significantly. The FPG is positively correlated with systolic BP significantly. The FGIR and QUICKI are negatively correlated systolic and diastolic $\mathrm{BP}$ significantly.

Table 2: Correlation of parameters with BP among study groups

\begin{tabular}{lll}
\hline & \multicolumn{2}{c}{$r$ value of Pearson's correlation coefficient } \\
\cline { 2 - 3 } Parameters & Systolic $B P(\mathrm{~mm} \mathrm{Hg})$ & Diastolic $B P(\mathrm{~mm} \mathrm{Hg})$ \\
\hline FPG $(\mathrm{mg} / \mathrm{dL})$ & $0.259^{*}$ & 0.230 \\
FI $(\mu \mathrm{IU} / \mathrm{mL})$ & $0.598^{* *}$ & $0.607^{* *}$ \\
FGIR & $-0.494^{* *}$ & $-0.518^{* *}$ \\
Log FI & $0.635^{* *}$ & $0.637^{* *}$ \\
QUICKI & $-0.596^{* *}$ & $-0.608^{* *}$ \\
\hline
\end{tabular}

*Significant $(p<0.05) ;{ }^{* *}$ Highly significant $(p<0.001)$

Table 1: Comparison of parameters among cases and controls

\begin{tabular}{llll}
\hline & Controls (mean \pm SD) & Cases (mean \pm SD) & $\begin{array}{c}\text { p-value of unpaired } \\
\text { student's t-test }\end{array}$ \\
\hline Period of gestation (weeks) & $34.36 \pm 1.69$ & $34.03 \pm 3.46$ & 0.57 \\
Age (years) & $23.51 \pm 2.68$ & $23.77 \pm 2.55$ & 0.68 \\
Systolic BP $(\mathrm{mm} \mathrm{Hg})$ & $113.0 \pm 5.34$ & $157.0 \pm 8.77$ & $<0.001^{\dagger}$ \\
Diastolic BP (mm Hg) & $73.67 \pm 4.9$ & $96.87 \pm 7.0$ & $<0.001^{\dagger}$ \\
FPG $(\mathrm{mg} / \mathrm{dL})$ & $80.49 \pm 5.50$ & $89.07 \pm 23.31$ & $<0.05^{\star}$ \\
FI $(\mu \mathrm{IU} / \mathrm{mL})$ & $6.06 \pm 1.89$ & $10.23 \pm 3.06$ & $<0.001^{\dagger}$ \\
FGIR & $14.61 \pm 4.91$ & $9.26 \pm 3.31$ & $<0.001^{\dagger}$ \\
Log FI & $0.76 \pm 0.17$ & $0.99 \pm 0.12$ & $<0.001^{\dagger}$ \\
QUICKI & $1.37 \pm 0.26$ & $1.02 \pm 0.12$ & $<0.001^{\dagger}$ \\
\hline
\end{tabular}

*Significant; ${ }^{\dagger}$ Highly significant 


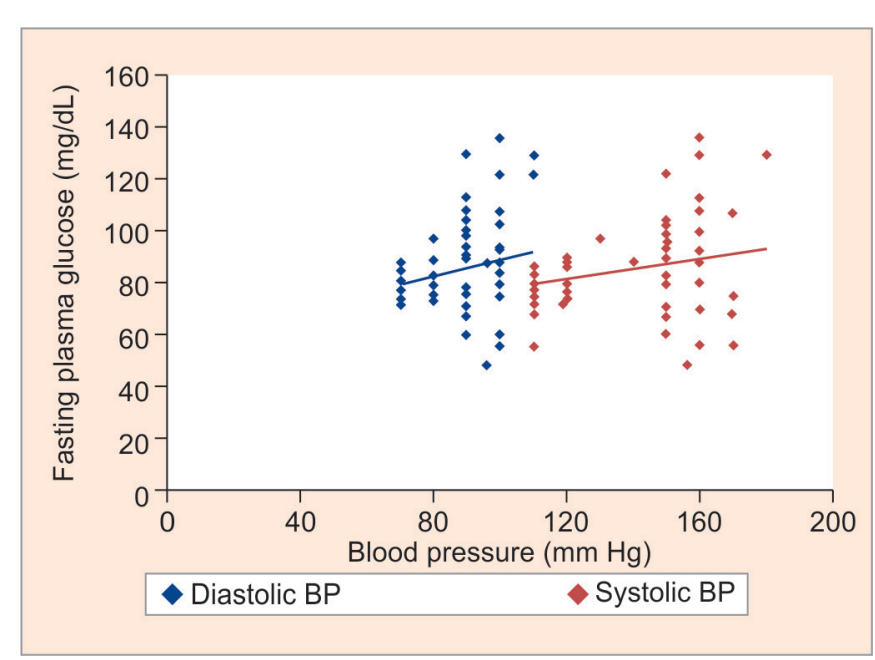

Graph 1: Correlation between FPG and BP

\section{DISCUSSION}

The knowledge about hypertensive disorders of pregnancy has been present since ancient times. ${ }^{1}$ Preeclampsia can affect all organ systems, most notably the renal, cardiovascular, brain, hematologic, and immunologic systems. These disorders are associated with increased mortality and morbidity both in mother and in fetus. ${ }^{13}$

This study was done to compare changes in IR in preeclampsia and in normal pregnancy. Age is one of the major factors affecting IR, and with an increase in age, there is a progressive increase in IR. ${ }^{14,15}$ Therefore, agematched cases and controls were selected to remove the bias. The IR increases along with advancement of pregnancy; ${ }^{16}$ therefore, cases and controls were also matched for period of gestation.

In our study, FPG and FI levels were significantly higher in cases when compared with controls. The findings are in accordance with Hamasaki et al, ${ }^{17}$ Ghosh et al, ${ }^{18}$ and Stefanović et al. ${ }^{19}$ Presence of IR is quoted as the main reason for elevation of fasting glucose levels in these studies. Lei et $\mathrm{al}^{20}$ stated that mild IR is noted in normal pregnancy in the form of higher FPG level and increased insulin secretion. These metabolic changes may have occurred to meet the metabolic demands of a growing fetus. These changes are found to be exaggerated in hypertensive disorders of pregnancy.

In our study, log FI was significantly higher, while FGIR and QUICKI were significantly lower in cases when compared with controls. These findings suggest increased amount of IR in cases as compared with controls. Presence of placental ischemia and inflammation leads to increased production of inflammatory mediators. ${ }^{21}$ Elevated levels of such mediators lead to alteration in insulin signaling pathway. As a result, development of IR is observed in such individuals. ${ }^{8}$ In our study, we found that systolic and diastolic BPs have significant positive correlation

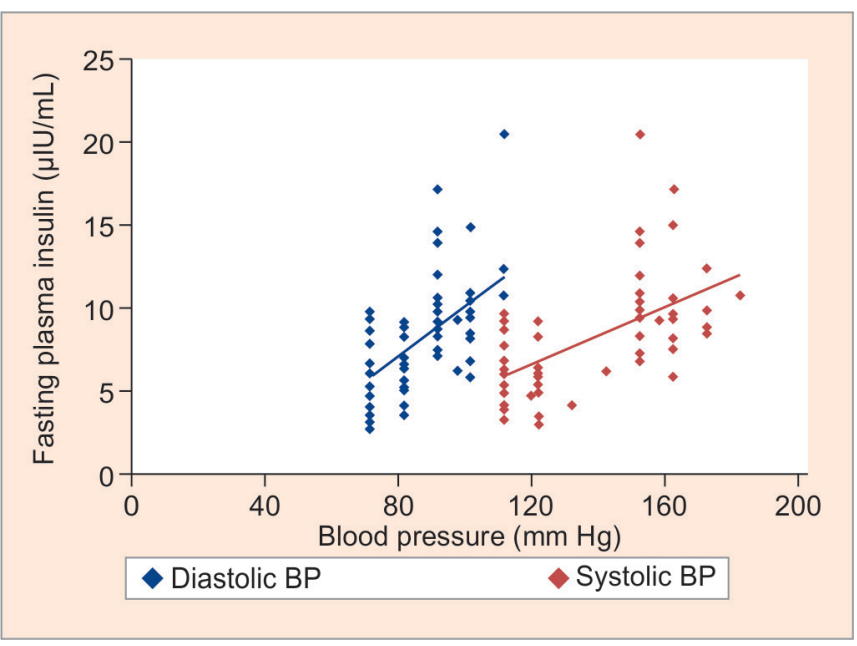

Graph 2: Correlation between FI and BP

with FI, while having significant negative correlation with QUICKI and FGIR. This suggests increase in IR as disease severity increases.

Elevated IR is associated with many maternal and fetal complications. Increased occurrence of premature labor, antepartum or postpartum hemorrhage, IUGR, or fetal overgrowth, etc., is seen in mothers suffering from increased IR. ${ }^{22,23}$ Presence of IR also increases risk of development of metabolic syndrome, diabetes mellitus, hypertension, hyperlipidemia, and cardiovascular disorders later in life. ${ }^{24}$

If women with hypertensive disorders of pregnancy are screened for presence of IR, timely lifestyle and dietary modifications can be prescribed to them. Such modifications can reduce impact of IR and may reduce occurrence of maternal and fetal complications..$^{25,26}$

\section{CONCLUSION}

Endothelial dysfunction and inflammatory imbalance in preeclampsia lead to development of IR in mother. Elevated IR is associated with maternal and fetal complications. If preeclamptic mothers are timely screened for IR, lifestyle and dietary modification can be prescribed to them, which can reduce complications during pregnancy, during delivery, and in later life.

\section{ACKNOWLEDGMENTS}

Authors would like to thank all the study subjects for being part of this study and their cooperation. The authors are also grateful to authors/editors/publishers of all those articles, journals, and books from where the literature for this article has been reviewed and discussed.

\section{REFERENCES}

1. Bell MJ. A historical overview of preeclampsia-eclampsia. J Obstet Gynecol Neonatal Nurs 2010 Sep;39(5):510-518. 
2. Shah, MR. PIH: the challenge. In: Shah M, editor. Hypertensive disorders in pregnancy. New Delhi: Jaypee Brothers; 2007. pp. 1-9.

3. Bansal, S. Hypertension in pregnancy. In: Desai P, Malhotra N, Shah D, editors. Principles and practice of obstetrics and gynaecology for post-graduates. 3rd ed. New Delhi: Jaypee Brothers; 2008. p. 100-107.

4. Cunningham, FG.; Lenevo, KJ.; Bloom, SL., et al. Pregnancy hypertension. In: Cunningham FG, Lenevo KJ, Bloom SL, et al., editors. Williams obstetrics. 23rd ed. New York (NY): The McGraw-Hill Companies; 2010. pp. 706-728.

5. Saleh RA, Dkhil MA. Structural changes of placenta in preeclamptic patients: light and electron microscopic study. Turk J Med Sci 2008 Jun;38(3):219-225.

6. Gilbert JS, Ryan MJ, LaMarca BB, Sedeek M, Murphy SR, Granger JP. Pathophysiology of hypertension during preeclampsia: linking placental ischemia with endothelial dysfunction. Am J Physiol Heart Circ Physiol 2008 Feb;294(2): H541-H550.

7. Powe CE, Levine RJ, Karumanchi SA. Preeclampsia, a disease of the maternal endothelium: the role of antiangiogenic factors and implications for later cardiovascular disease. Circulation 2011 Jun;123(24):2856-2869.

8. Catalano PM. Obesity, insulin resistance, and pregnancy outcome. Reproduction 2010 Sep;140(3):365-371.

9. DeFronzo RA, Ferrannini E. Insulin resistance: a multifaceted syndrome responsible for NIDDM, obesity, hypertension, dyslipidemia, and atherosclerotic cardiovascular disease. Diabetes Care 1991 Mar;14(3):173-194.

10. Sack, D. Carbohydrates. In: Brutis C, Ashwood E, Bruns $\mathrm{D}$, editors. Teitz textbook of clinical chemistry and molecular diagnostics. 4th ed. New Delhi: Elsevier; 2006. pp. 868-875.

11. Kricka, L. Principles of immunochemical techniques. In: Brutis C, Ashwood E, Bruns D, editors. Teitz textbook of clinical chemistry and molecular diagnostics. 4th ed. New Delhi: Elsevier; 2006. pp. 219-244.

12. Mather KJ, Hunt AE, Steinberg HO, Paradisi G, Hook G, Katz A, Quon MJ, Baron AD. Repeatability characteristics of simple indices of insulin resistance: implications for research applications. J Clin Endocrinol Metab 2001 Nov;86(11): 5457-5464.

13. BackesCH,Markham K,MooreheadP,Cordero L,NankervisCA, Giannone PJ. Maternal preeclampsia and neonatal outcomes. J Pregnancy 2011 Feb;2011:214365.
14. Jung CH, Jung SH, Lee B, Rosenberg M, Reaven GM, Kim SH. Relationship among age, insulin resistance, and blood pressure. J Am Soc Hypertens 2017 Jun;11(6):359-365.

15. Karakelides H, Irving BA, Short KR, O’Brien P, Nair KS. Age, obesity, and sex effects on insulin sensitivity and skeletal muscle mitochondrial function. Diabetes 2010 Jan;59(1):89-97.

16. Sonagra AD, Biradar SM, Dattatreya K, Murthy DSJ. Normal pregnancy-a state of insulin resistance. J Clin Diagn Res 2014 Nov;8(11):CC01-CC03.

17. Hamasaki T, Yasuhi I, Hirai M, Masuzaki H, Ishimaru T. Hyperinsulinemia increases the risk of gestational hypertension. Int J Gynecol Obstet 1996 Nov;55(2):141-145.

18. Ghosh A, Freestone NS, Anim-Nyame N, Arrigoni FIF. Microvascular function in pre-eclampsia is influenced by insulin resistance and an imbalance of angiogenic mediators. Physiol Rep 2017 Apr;5(8):e13185.

19. Stefanović $M$, Vukomanović $P$, Milosavljević $M$, Kutlešić $R$, Popović J, Tubić-Pavlović A. Insulin resistance and c-reactive protein in preeclampsia. Bosn J Basic Med Sci 2009 Aug;9(3):235-238.

20. Lei Q, Lv LJ, Zhang BY, Wen JY, Liu GC, Lin XH, Niu JM. Antepartum and post-partum markers of metabolic syndrome in pre-eclampsia. J Hum Hypertens 2011 Jan;25(1):11-17.

21. Gupta T, Arora S, Kumar A, Gupta N, Gupta S. Evaluation of maternal serum levels of cell adhesion molecules and endothelial inflammatory markers in normal pregnancy, gestational hypertension and pre-eclampsia. Int J Reprod Contracept Obstet Gynecol 2017 Jun;6(6):2231-2237.

22. Scholl TO, Sowers M, Chen X, Lenders C. Maternal glucose concentration influences fetal growth, gestation and pregnancy complications. Am J Epidemiol 2001 Sep;154(6):514-520.

23. Imoh LC, Ogunkeye OO, Isichei CO, Gadzama AA, John C, Ocheke AN. Severe maternal insulin resistance in pregnancy: an independent predictor of fetal macrosomia. J Med Trop 2016 Oct;18(2):73-78.

24. Seely EW, Solomon CG. Insulin resistance and its potential role in pregnancy induced hypertension. J Clin Endocrinol Metab 2003 Jun;88(6):2393-2398.

25. Tobias DK, Zhang C, van Dam RM, Bowers K, Hu FB. Physical activity before and during pregnancy and risk of gestational diabetes mellitus: a meta-analysis. Diabetes Care 2011 Jan;34(1):223-229.

26. Way KL, Hackett DA, Baker MK, Johnson NA. The effect of regular exercise on insulin sensitivity in type 2 diabetes mellitus: a systematic review and meta-analysis. Diabetes Metab J 2016 Aug;40(4):253-271. 